\title{
Marks of Obsession:
} Appearance, Transformation, Pain, and the Abject Female Body

By Anna Pollice

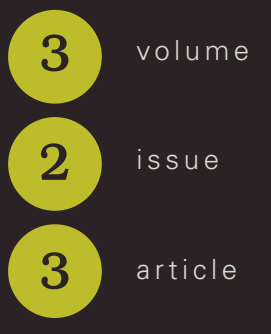

\section{KEYWORDS:}

\section{FEMALE BODY}

SELF-OBJECTIFICATION

\section{ABJECT}

PAIN

TRANSFORMATION

\section{Abstract}

Using a conceptual framework, this creative research explores women's bodies as they transform. The body of work that emerged through creative practice engages in existing discourse on body image and the dissemination of ideal images by the Western fashion system. Through a series of artistic processes that transform images to the point of dissolution, this work considers how the self is embodied through varied experiences of transformation. Marks of Obsession considers images of the female body as abject and, visualized through self-objectification and pain, attempts to comprehend and empathize with the self, as it supports the body to realize dominant social ideals. 


\title{
INTRODUCTION
}

Consumer culture advances the dominant belief that through transformation and consumption, the future embraces the possibility of something better (Coleman 5; Featherstone 1991: 22, 2010:197). Within a social and bodily context, physically transforming the body both internally and externally as a means of approximating idealized images promises the possibility of a better quality of life and of happiness (Coleman 2; Featherstone 2010: 200; Ringrose \& Walkerdine 2008: 230). Yet varying degrees of physical transformation, and the mental and emotional discipline required to enact such transformations, cause visible and/or invisible damage to both the body and the self, resulting in embodied pain that cannot be shared through words or language (Ahmed 2015; Bordo 2003; Fahs 2017; Scarry 1985).

\section{This research creatively explores appearance, transformation, and pain in relation to the abject female body.}

\begin{abstract}
Thisexploration developed from a personal interest in how women see ourselves reflected in a contemporary fashion system, and how this reflecti $\mathrm{n}$ impresses upon us a social identity. Within this research, and through this material exploration, I question how we, as women, identify with the social expectations of a system that visually defines a fashionably sized and shaped body, and consider to what extent we will go to achieve it. Thework questions if body transformation, as a response to ideal bodies, can be read as a sign of one's pain.
\end{abstract}




\section{AN ENDURING IDEA(L)}

Self-image encapsulates ideas of appearance and impacts one's viewpoint and sense of contentedness. Though not one's reality, self-image is fabricated on acuity of one's reality, influenced by how one believes they are perceived by others and society. Body image develops through a subjective picture of one's own body, influencing the personal judgement of one's physical appearance, a judgement that arises from both self-surveillance and the reactions of others. Ideologies of the self and the body are constantly changing, thus evoking inquiries into the intricate and personal connections women have to their bodies. This work is a personal reflecti $\mathrm{n}$ on how I connect to my body, its dramatic changes over time, and what those changes mean to me. For myself, body weight and size were not only measurements that related to an ideal body, but non-arbitrary numbers that, when positioned on a continuum between "ideal" and "not ideal," determined my happiness and self-worth. I designed a continuum with specific bodies in mind - bodies I aspired to and bodies I feared becoming. Images of aspirational bodies on my continuum were predicated on the thin ideal venerated in the Western fashion system.

As a young girl, I learned to see my body as something I could control, manipulate, change, and make better. Better, for me, meant thinner. I believed that a better, thinner body would mean a better me. This irrational thought pattern, one I entertained for years, and perhaps continue to do so despite my better understanding, reinforced many dangerous notions. For one, I naïvely believed that changes in my body would coincide with changes in my self-esteem, and so it became imperative that I reposition myself on the ideal/ not ideal continuum. The momentum I experienced in making extreme dietary choices to "improve my health" swung my imaginary pendulum far in one direction causing weight loss, resulting in a smaller body, in that way making me happy. I have, however, experienced my body transform in both pendulum directions many, many times, causing dramatic changes in weight and size, and in perceived happiness and self-worth. The focus was what others saw and how I saw myself relative to a social ideal.

I situate myself within this work as a woman having embodied varying degrees of happiness and self-worth based on numbers depicting weight and size, and their positioning on a continuum that polarized "ideal" and "not ideal."

\section{CONTEXTUAL OVERVIEW}

Appearance is central to one's sense of self (Firth and Gleeson 250) and signifies the perception of one's physical body, understanding that the body is not only a thing but a vehicle for experience. Perception links mind and body, relegating the body to what the individual mind can see (Grosz 41-42). As Elizabeth Grosz explains, the body is "my being-to-the-world" through which all information and knowledge is received and meaning made (87). The body is then a condition through which it is possible to have relationships with objects and the world (Fraser and Greco 44; Grosz 86). 
As a social agent, the lived or sensing body facilitates all of our interactions with other bodies and objects in the world, including the way it is observed and touched by others.

Foucault's perspective on the body is seen, evaluated, and reacted to by others, influencing one's personal evaluation of their body and self. How the self evaluates the body depends on assumptions that exist about gender, race, ethnicity, class, ability, age, and attractiveness and, as these assumptions change, so too does the basis of evaluation, and consequently how the individual is socially and culturally conditioned to choose to transform their body. For Foucault, the body is malleable and unfinished and, through various disciplinary practices, can be transformed (Blackman 134). This form of disciplinary power encourages the individual to come, on their own terms, to want or desire specific social $\mathrm{w}$ ys of being.

\title{
In this way, certain norms or ideals become part of the individual's routine-self-monitoring and self- regulation are hardly perceptible.
}

\begin{abstract}
Women's bodies exist in a sociocultural context through which they communicate meaning (Fredrickson and Roberts 174). Within this context, physical appearance becomes a type of currency for women, translating physical beauty to power (Unger qtd. in Fredrickson and Roberts, 178), positioning women on a hierarchy. The notion of women critically judging their own bodies as objects to be appreciated by others is a phenomenon called self-objectifi ation (Calogero et al. 7). Fredrickson and Roberts originally theorized self-objectifi ation as "a repercussion of being viewed by others in sexually objectifying ways that over time, individuals may be coaxed to internalize an observer's perspective on self"
\end{abstract}


(179). Th ough this lens, the focus for women is on "what others see" (Christler and Johnston-Robledo 21 ), adopting a view of their own bodies from an observer's perspective (Fredrickson and Roberts 178). Cooley (1902) used the phrase "looking-glass self," maintaining that an individual's sense of self is socially constructed, reflecting ways that others view and treat them (Fredrickson and Roberts 179; Featherstone 1991: 194). A woman's sense of self then develops through the lens of an evaluating gaze, one that she turns on herself to self-objectify. This external view makes her self-conscious and facilitates self-monitoring and constant self-evaluation viewing herself as "not good enough" and in constant need of improvement (Calogero et al.10).

From this perspective arises the notion of the abject body, and more specifi ally, the abject female body as a project to be improved upon. Julia Kristeva (1982) defined the abject as "that which disturbs identity, system and order ... and does not respect borders, positions, rules" (4). The notion of abject is unsettling because it disrupts the boundaries that exist between the self and other, and the body as a "self-contained individual" (Blackman 93). Judith Butler theorizes the "other" or the "abject" as a new border of the body that is created when part of one's original identity is rejected. She argues that the boundary between the inside and the outside consolidates identities to exclude some while allowing others to dominate for the purpose of "social regulation and control” (Butler 170). This theorization makes the abject shameful and disgusting and forces one to want to purge whatever is abject from their identity (Ringrose and Walkerdine 234). This sense of the abject not only consolidates identities for the purpose of social regulation but also creates a desire to want to transform and improve the self as a way to separate from the abject.

The abject female body is described by Ringrose and Walkerdine as a working-class woman who lacks in desirability, both as object and subject, and is therefore unable to consume and be con- sumed, making her a viable subject for transformation (228). Transformation can be defined as "a logic that both promises potential and casts some bodies as failing in needing, achieving and maintaining change" (Coleman 3). In a consumer culture, transformation, and the products consumed to achieve it, is what individuals cling to in order to preserve and meliorate the self. In Ringrose and Walkerdine, a woman is considered both the object and subject of consumption, suggesting that in order for a woman to be beautiful and successful, or "consumed," she must personify a particular appearance (230) that is created through transformation. Theallure of recreating the self and identity through transformation, is that of happiness.

Fashion, as a way to self-regulate the appearance of the body, can be a less invasive process of transformation (Firth and Gleeson 250). Beauty labour, including dieting and exercise, can offer extreme means used to alter appearance; nevertheless, it is both the invasive methods and the not-so-invasive methods required of beauty and appearance that together become excessive, simultaneously affecting pain while seemingly caring for the body. In The Cultural Politics of Emotion, Sara Ahmed explains that pain is not simply the result of bodily damage, and questions what pain does rather that what pain is. Feelings of pain bring our focus back to the body, both to our sensing body and to the emotional one (Ahmed 26). Thesurface, or the body, is felt through what Elaine Scarry in The Body in Pain: The Making and Unmaking of the World refers to as "negation" (15); when something outside of me, outside the border of my skin, pushes against me and against this border. Th ough her reading of Scarry, Ahmed explains that pain involves this movement from the outside to the inside, allowing one to feel that there is a border at all and to hence feel physical pain. She asserts that we are shaped through our reaction to other bodies and objects, arguing that our emotions create surfaces and boundaries that define objects (10), that define individual bodies. 
For Ahmed, pain can be understood as something foreign to the body, something one wants to be rid of, something that forces one to "attend" to the body or bring attention to it. As such, one becomes aware not only of the body, but the body in relation to other bodies and objects (Ahmed 27). In reading Ahmed's perspective on pain, I see how idealized images of the body that exist in the world inhabited by the body, can move to the inside, making one aware of their own body in relation to those images. Transformation, as a reaction to these images, reforms the body (Ahmed 26).

The language needed to communicate the feeling pain does not exist. Pain destroys language and so there exist no words to adequately describe the feeling of pain (Ahmed 22; Scarry 13). Scarry argues that "to have pain is to have certainty and to hear about someone else's pain is to have doubt" (Scarry 13). In this way, pain is invisible, objectless, yet this "objectlessness" is what allows for "imagining" (Scarry 161-162). We can imagine someone's pain by acknowledging how the body reacts to it.
METHODOLOGY

\section{The emergent body of work,} Marks of Obsession, is a result of many processes and discoveries. Through creative practice, I used photography to capture images of my body, and then using a method that involved transferring the photographed images onto an acrylic medium, I transformed the images.

The research methodology involved an autoethnographic approach where I, the researcher, am both the subject of the research and the voice of the narrative (Chaplin 243), captured through using photographs of my body, and reflecti e journaling to record the process of creation and the effects of my embodied transformation. Autoethnography as a methodology includes the analysis of the researcher's personal experiences in order to understand cultural experiences and in this way provides knowledge that does not yet exist (Chaplin 243). An autoethnographic project includes elements of the research process that, in a more conventional setting, are not always included, such as "personal opinion, doubts, worries and confessions" (Chaplin 242). I did not intentionally set out to use autoethnography as a methodology; however, this work is personal on many levels that could not be excluded from the research, from the visual material to the personal reflecti ns of transformation. The methodology then transformed in response to this new understanding. 


\section{CREATIVE PRACTICE}

This body of work emerged from creative practice. Practice-led research considers how the act of making art can be used together with research as a way to create knowledge (Makela 157). In Makela's article, "Knowing Th ough Making: The Role of the Artefact in Practice-led Research," the exploration or, "the process of making," and the body of work or, "the object," together are what make up the "source of knowledge" (Makela 158); this is the basis of "knowing through making" (Makela 158). Makela argues that practice-led research suggests the object created through the creative process embodies the knowledge gained through that process and is therefore inextricably linked to the object (158). Marks of Obsession has emerged through a symbiotic relationship between research and creation where the literature and research direct the making and the making inspires the research.

Creative practice as research is driven by personal experience. In her paper, "Experiential Learning in Practice as Research: Context, Method, Knowledge," Estelle Barrett argues that art as research extrapolates new knowledge from everyday experiences (115). She draws on the work of many to emphasize that knowledge is experiential and that learning begins with lived experiences and reflecti ns on those experiences (Barrett 119). Although refle tion relies on memory and may be biased, creative practice is impossible without it (Skains 88). It is through self-reflecti $n$ that experience becomes intellectual (Barrett 117).
Not to be overlooked in the process of creation is the element of serendipity (Makri and Blandford 2). Serendipity plays a signifi ant role in both the process of making and the body of work. Serendipity can be defined simply as "insight coupled with chance" (Fine \& Deegan 436 qtd. in Makri and Blandford 3) and brings together inspiration and intellect that often leads to what Skains refers to as "eureka moments" for the artist or maker (90). Within this work, journal reflecti ns highlight serendipitous occurrences throughout the process of making, connecting to periods of inspiration, furthering both the literal research and the making.

\section{RESEARCH METHOD}

The images used for this work were produced by my daughter, an amateur photographer, using an iPhone. The photographs are of my body, wearing a white one-piece swimsuit, taken in an empty room in my home. Several images, sharing similar qualities, were chosen for this work. The outfit for example, allows for the size and shape of the body to be revealed, and the amount of exposed skin relates to the skinlike quality of the work and creates visceral engagement. The poses are direct and allow for transformations of the body through the image to be visible. In many circumstances it is near impossible to conceal the true size and shape of a body when wearing a swimsuit and so photographing the body dressed this way became integral to the exploration of transforming it. Mainstream media represents fashionable female bodies through garments that reveal specific size, shape and skin. This exploration attempts to disrupt a monolithic fashion image. 
Thefirst image was printed in colour using an ink-jet printer and then transferred onto an acrylic medium, creating an acrylic "skin." The image transformed when the acrylic skin was stretched to beyond its point of resistance, causing "wounds" or breaks at its weakest points, showing marks of damage on the skin. Its visceral quality shared both beauty and pain. This image became the focus of this work in both transformation and multiplicity (Figure 1). Creating multiples of the initial image inspired not only the work but the process and the practice. Recreating the initial image became the goal. This repetition proved both futile and fruitful. A journal entry notes:

Nov. 24/19: One image, one process-that was the catalyst for this obsessive attempt to recreate and reproduce that exact effect ... hundreds of copies later, none have proved a worthy duplicate. 
The journal entry speaks to two fundamental concepts. First, the notion of repetition is only partially accurate. The actions of the method are repeated, but the results are not. Second, there is an acceptance of not being able to replicate the original work, however, within that acceptance lies a compulsion to continue to try. The process of exposing multiple copies of the same image to multiple mediums, and varying degrees of strength while stretching the skins is part of the obsessive quality of this work; the method both facilitates and promotes the obsession. This obsessive behaviour has culminated in nearly two hundred artifacts based on one image (Figure 2 and Figure 3).

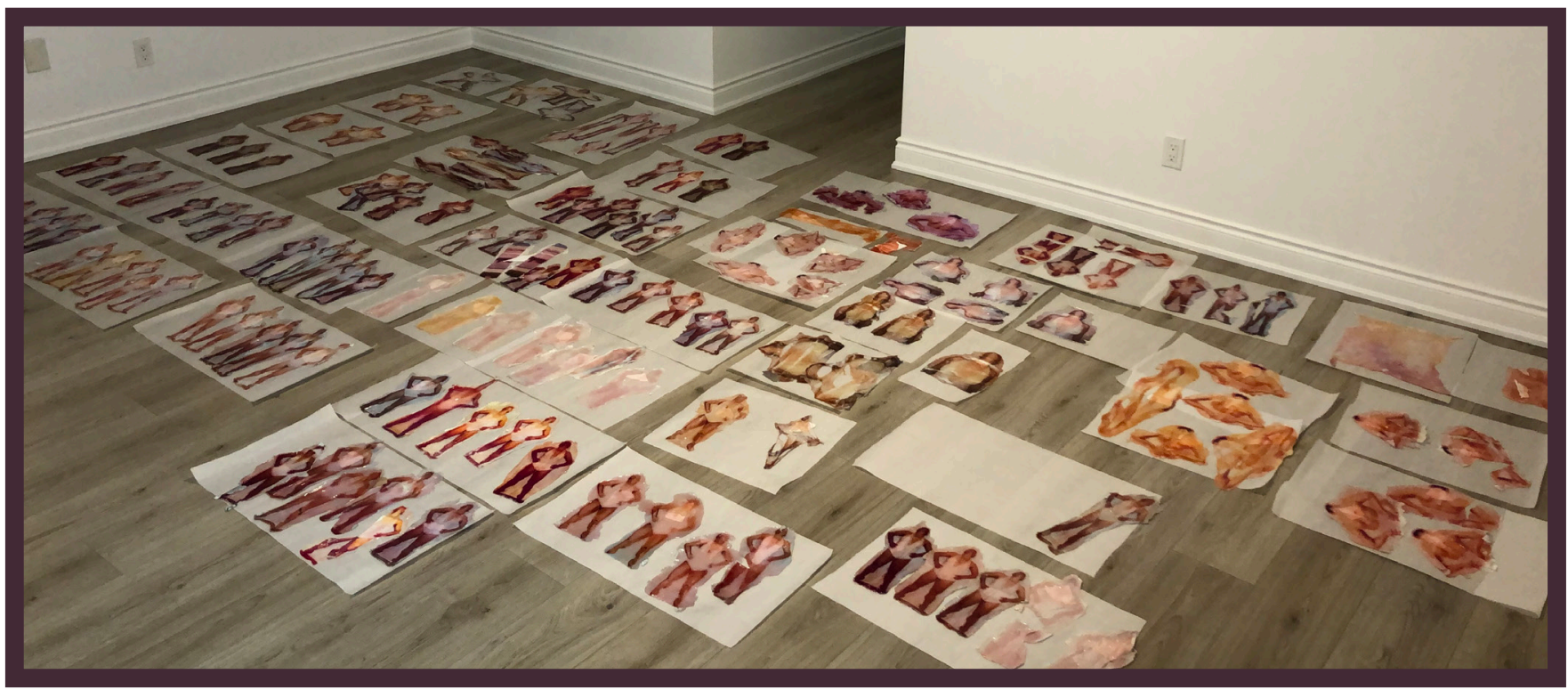

FIGURE 2 Obsession, process. 2020. Toronto. 


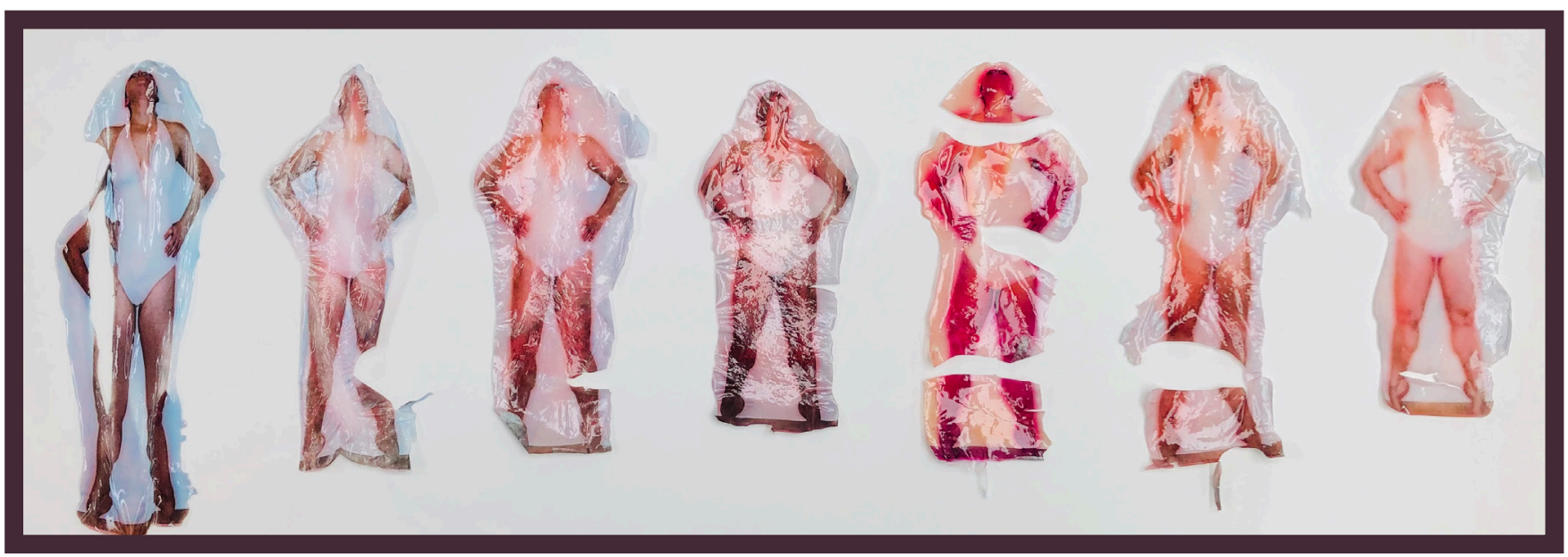

FIGURE 3 Vertical Stretch Series \#1. 2019. Toronto.

\section{No two transformed images are alike, and each medium translated a different quality to the final work.}

Some were thick and felt very much like vinyl; others thin and papery with a sense of fragility. Some mediums forced the transformation back to the original shape and size, while others allowed the image to stretch without any resilience, retaining the transformation. A pattern was emerging, one that demonstrated the advantages of certain mediums to direct specific outcomes. A journal entry propelled a slight revision, allowing another perspective.

Dec. 15/19:The more skins I make, the more familiar I become with the medium and how it will react ... I find that I am controlling the situation more and more. I am starting to see a pattern and a desired outcome.

This reflecti $\mathrm{n}$ inspired the horizontal stretching of the images, creating very wide and corpulent bodies, and considered that bodies transform in many different ways. A change in the direction of the transformation encompassed one direction of transformation and also its opposite. The vertical and horizontal manipulation of this image, in its many iterations, created very long or very wide, grossly distorted bodies that appeared emaciated or corpulent beyond recognition (Figure 4 and Figure 5). These images represented only one type of transformation at a time. The process of transformation between the two had not yet been considered. This inspired the development of the second series within this body of work. 


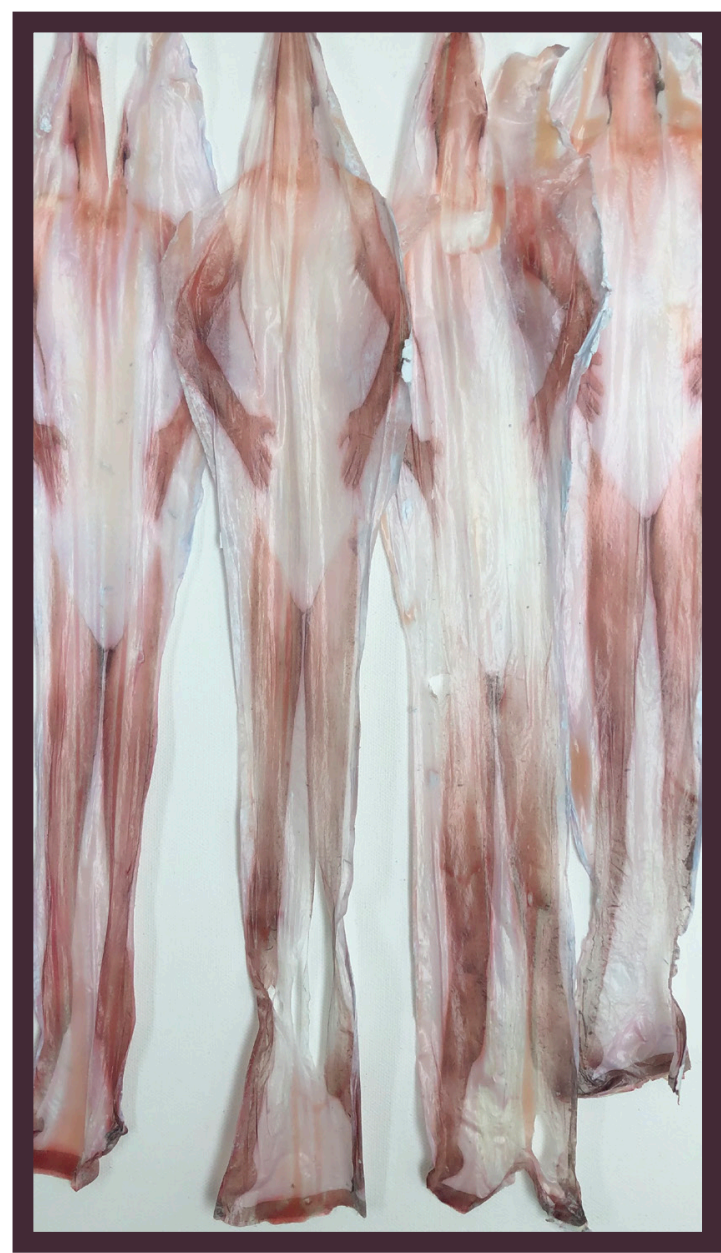

FIGURE 4 Vertical Stretch Series \#2. 2019. Toronto.

The vertical and horizontal manipulation of this image, in its many iterations, created very long or very wide, grossly distorted bodies that appeared emaciated or corpulent beyond recognition (Figure 4 and Figure 5). These images represented only one type of transformation at a time. Theprocess of transformation between the two had not yet been considered. This inspi ed the development of the second series within this body of work.
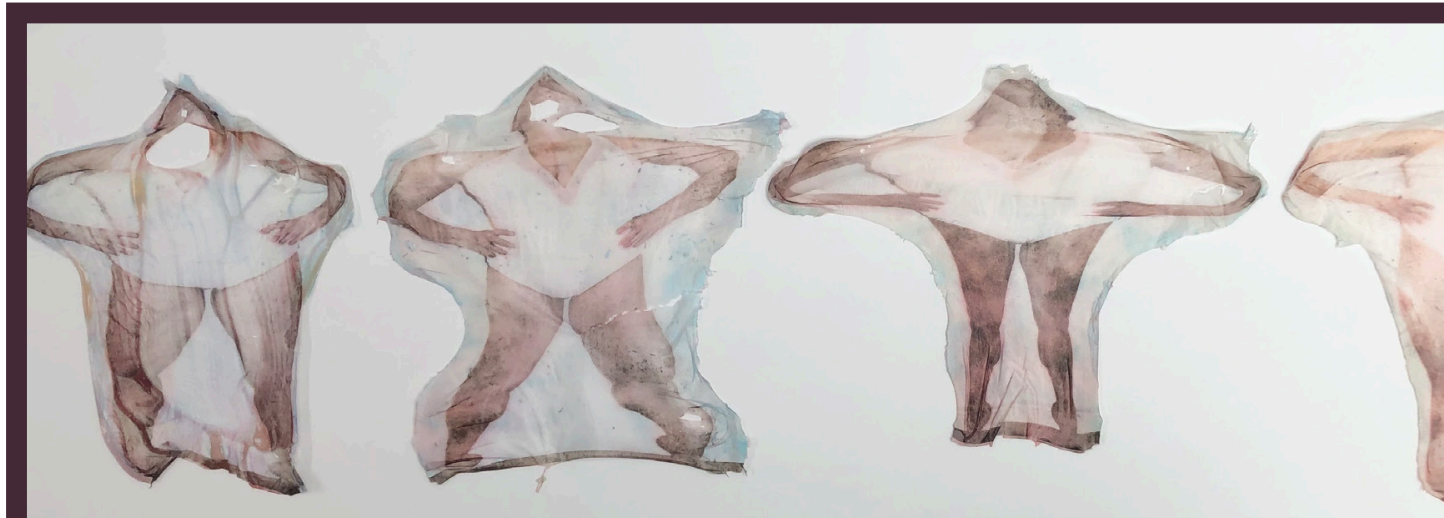

FIGURE 5 Horizontal Stretch Series \#1. 2019. Toronto. 


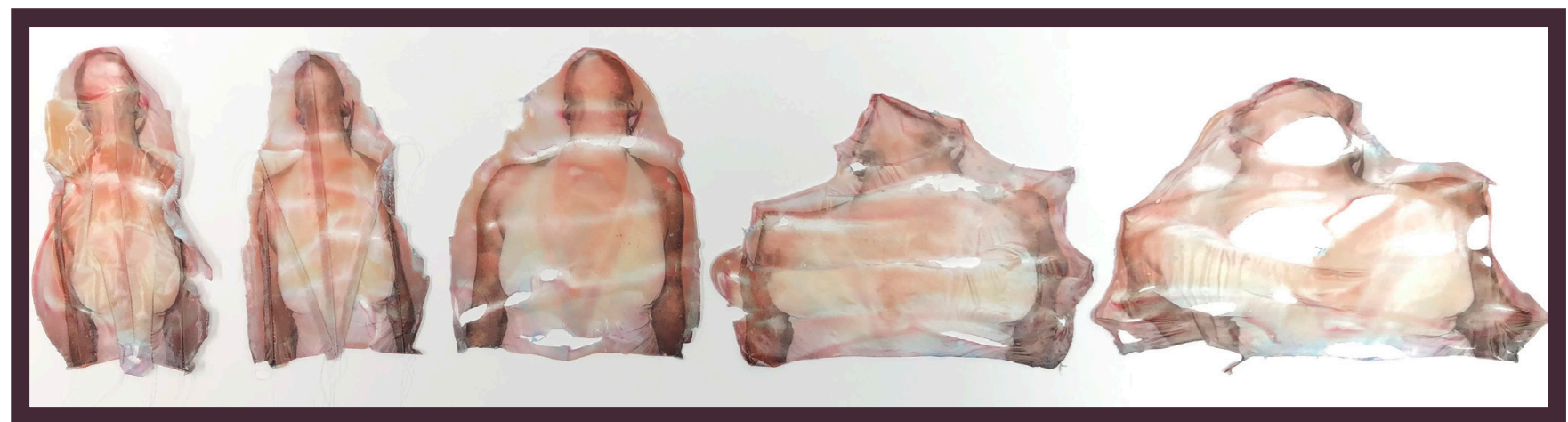

FIGURE 6 5-Figure Series \#1. 2019. Toronto.

Here, an altogether different image was used. Similarly produced, this image was printed fi e times, each treated with the same medium. Two of the skins were stretched horizontally, one more severely than the other, and two skins were vertically darted using a sewing machine, to create a horizontal compression of the body, again, one more severely than the other. In succession, the fi e images mimic the gradual movement from one extreme to another. The effect of this method created images that were so far removed from the original they became unrecognizable (Figure 6 and Figure 7). A reflecti $\mathrm{n}$ of this body of work was entered on December 16, 2019:

Dec 16/19: I find myself contemplating boundaries. Boundaries define a space, in this case, a body. What is a body without boundaries? The body is stretched so far beyond its boundaries it doesn't even look like a body anymore. It's alien-like, foreign, abject. Surpassing boundaries makes a body abject. Its appearance toggles between polarities of extreme distortion to the point where I am forced to question if it is still considered a body. Is there still value in it at either end of the continuum?

This journal entry reveals a very real and emotional narrative that exists between what is and what could be allowing the polarities to coexist within the work. The images here take on entirely different forms, bleeding through the boundaries of what a body should look like, transforming into images that reference raw flesh on one end and alien on the other. The e is a dissolution of the body.
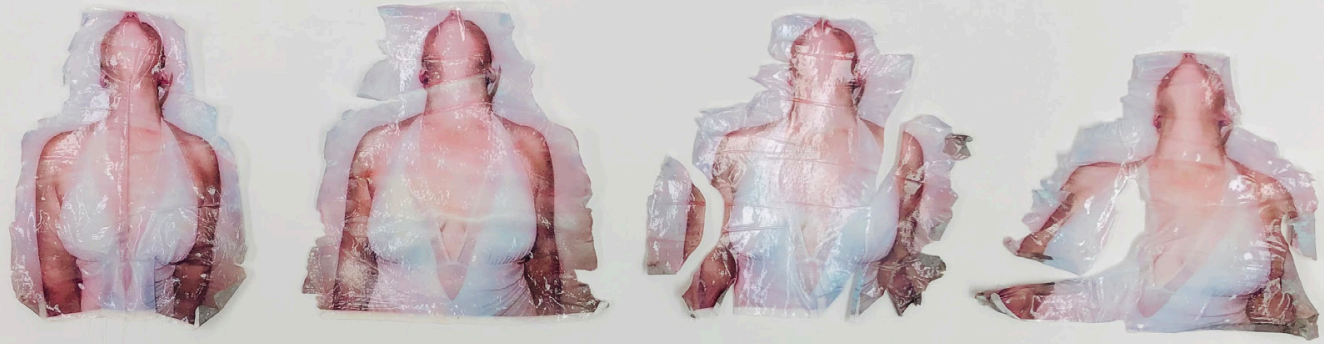

FIGURE 7 5-Figure Series \#2. 2019. Toronto. 
The most recent series evolved serendipitously when it became clear that the work thus far did not consider the multiple directions of body transformations. This realization felt like a "eureka moment" (Skains 90) and prompted further investigation. Here, all images were used, treated to the same medium, and severely stretched horizontally. Thesestretched images were further transformed by stitching vertical darts to compress the body back to its original shape, or at the very least, back to a social ideal. The following journal entry illustrates the ideation of multiple transformations:

Feb 18/20: The body will always bear the mark of change or transformation, of damage and pain. This next series takes the image as it were to extreme proportions in width, stretching and expanding, taking up more physical space but becoming more invisible. But just as swiftly, the body changes, again, shrinking and minimizing in size, taking up less physical space, but becoming even more visible. The marks, although well concealed, exist.

Although the images that have emerged here maintain a reference to a human body (Figure 8 and Figure 9), they bear the marks of transformation without erasure and expose evidence of damage to the body. The transformed images make a strong connection with the reality of body transformation in relation to an ideal, and embody that knowledge.

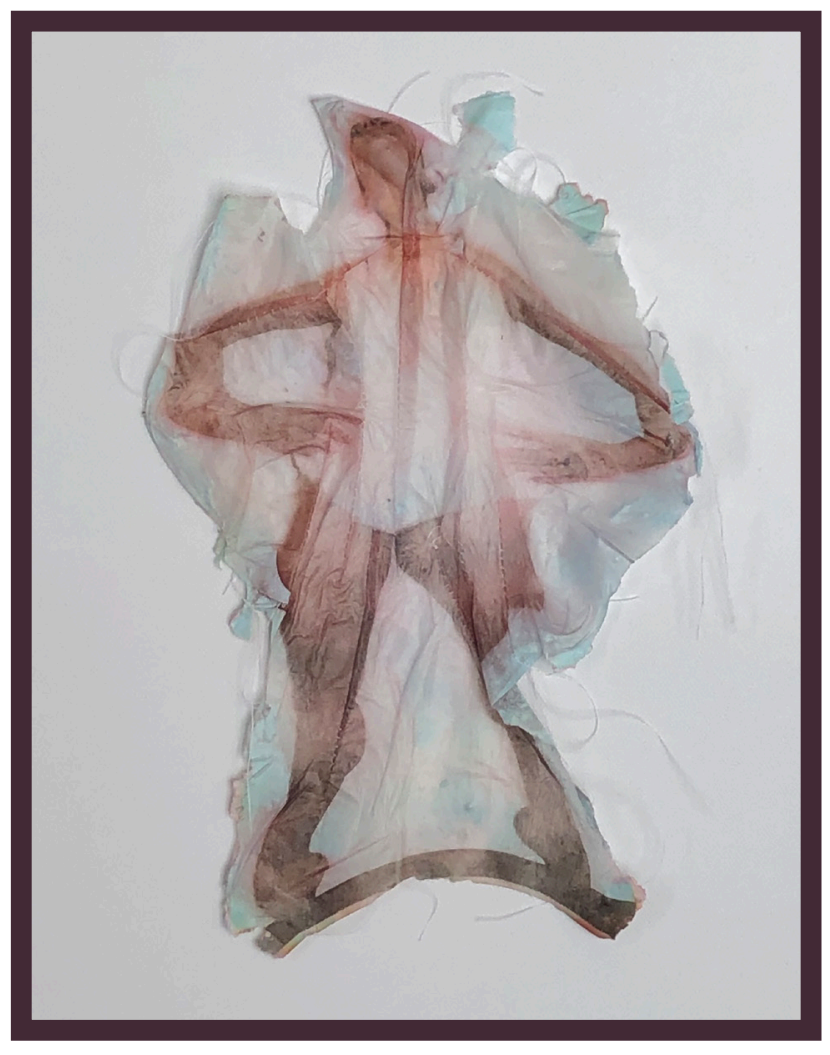

TOP: FIGURE 8 Stretched \& Stitched \#1. 2019. Toronto. BOTTOM: FIGURE 9 Stretched \& Stitched \#2. 2019. Toronto.

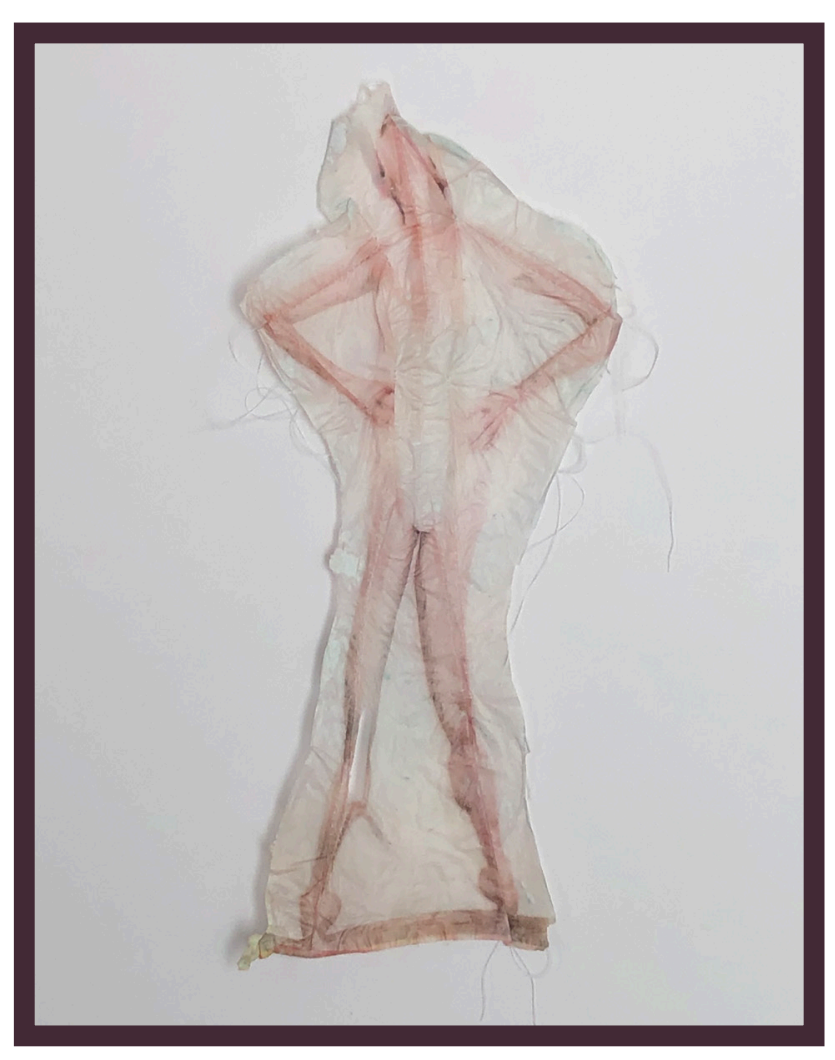




\section{INTERPRETATION}

Thee bodies of work materialized from this ideation phase, each similar in concept and method but unique in their perspective of transformation and relation to the body.

\section{Subsequently, three key themes emerged that relate the work to discourse of body image and body transformation: the resilient body, the abject body, and the damaged body.}

The work and processes involved express a complex series of interrelated subjects, including transformation and identity in relation to a Western contemporary fashion ideal of the female body.

\section{THE RESILIENT BODY}

Theresilient body is one that is able to bend but not break. It experiences both stress and trauma but recovers quickly. Within this work, resilience indexes an important theme both materially and as a metaphor for extreme body transformation. To a large degree, the medium used to create the pieces dictate the outcome. Some mediums allowed the image to stretch and retain its new shape while other mediums forced the transformation to revert back. We can view this as a characteristic of the medium. However, when considering the pendulum, gravity forces it to be resilient in a sense, obliging it to eventually find its equilibrium. The body too, bearing cultural inscriptions, transforms, at times to extremes, but its natural tendency is to "bounce back" or at the very least move closer to the centre.

The repeated process of vertically stretching the skins proved instrumental in allowing me to recognize my own embodied experience in using various techniques to transform my body. The process of stretching each image vertically created a longer, leaner appearance, one that more closely mimicked that of elongated fashion illustrations. While in reality, I could not lengthen my body, I used techniques such as diet and exercise to create a leaner body, one that through an internalized evaluating gaze ensured my movement along the ideal/not ideal continuum, towards what I perceived as "ideal." My resilient body, however, forced a continuation of that transformation. I learned that without the strict constant discipline needed to construct a slender body, the body continues to change in ways that are not always intended but perhaps needed.

In this work there is decay, there is damage and the bodies are broken, but there is also resilience. Physical bodies that transform through the technologies of excessive diet and exercise, reaching one unsustainable extreme then forced to "bounce back," essentially recover from the trauma of change and although do not revert back to their original form or starting point, do continue to transform. 


\section{THE ABJECT BODY}

The abject body is a stigmatized one. Butler's theorization of abject consolidates identities for social control where rejected identities are excluded (Butler 170), making the abject disgusting and encouraging rejection of the abject identity. For many women, the idea of disgust shapes ideas about the self, including notions of body image, ability, and self-worth, and, through social processes, disgust regulates behaviour and delineates hierarchies (Fahs 85). This creates a desire to want to change and meliorate the self as a way to separate from the abject. A separation from abject applies not only to the self but to the appearance of the body.

Viewing the images in this work through a process of transformation where bodies at either end of the continuum reference raw flesh or non-human entities considers a disruption in identity and a dissolution of boundaries that exist between not only subject and object but self and other, or the abject. For Kristeva, "the abject is edged with the sublime" where she describes the sublime as a delicate part of the abject that elicits pleasure (11). In this way, the work is at once disturbing and alluring, enticing the viewer to want to continue to look at and possibly touch the work, contemplating its beauty, while at the same time reckoning with a sense of abhorrence and disgust. Thisis the pleasure Kristeva references. Disgust, however, acts as a way for women to control and regulate their "unruly" bodies, and shape ideas of the appearance of those bodies (Fahs 84).
Transitioning my own body from one extreme to the other encouraged the very sensation of abjection that Kristeva describes. The e coexisted within me a sense of horror and beauty with the physical changes I incurred and a feeling of attraction and disgust for a body that was mine to care for. From the perspective of others, however, my thin body, and later my fat body, evoked both feelings of beauty and suffering, of admiration and concern.

The desire for transformation is an extension of a culture that favours and privileges certain bodies over others. Transformation is a way of purging that which is socially deemed abject or disgusting. This work depicts the body as "not good enough" and in need of transformation as a way to rid the body of that which is not good enough. The transformed images in this body of work not only impress upon the viewer a sense of escaping the abject but the very transformation blurs the lines between subject and object, self and other, creating, in a very real sense, abject bodies. Once transformed, the bodies negate boundaries and appear brutal and objectified Although the aim of the transformation was to shed an abject identity, somewhere along the ideal/not ideal continuum, the essence of creating a beautiful identity shifted to bodily and emotional pain.

\section{THE DAMAGED BODY}

The damaged body is one that is evidenced by the experience of transformation through marks on the body. Marks on the body are the result of healed wounds caused by some 
form of pain. Wounds or scars act as the site of transgression, communicating that something has been impressed upon the body and caused pain (Ahmed 27). Th y are a reminder of what caused them and leave internal scar tissue that perhaps cannot be cared for and healed in the way that superficial wounds can be. The e is a dichotomy that exists within the damaged body between what is visible and invisible. Wounds and scars on the body are visible, the emotional pain, however, is not visible, yet through the process of transformation, the two coexist.

Transformation can be viewed as both the cause of pain and a reaction to the feeling of pain. The notion of pain, as both a desire to achieve an impossible ideal and the beauty labour involved, is embodied. Ahmed argues that we become aware of our bodies when we are in pain but pain is only realized when we connect with others (bodies or objects). Within Marks of Obsession, transformation, both of the material objects and of my own body, acts as a response to my embodied pain felt when consistently connecting with images of perceived ideal bodies. For myself, transformation is taken up by a desire to change the body, to improve by making it thinner, as a way to make pain leave the body, or the self (Ahmed 27). Many have argued that pain is "private and lonely" (Kotarba 1983 and Melzak and Wall 1996 in Ahmed 2015; Scarry 1985), and because of this, impossible to know what someone else's pain feels like. However, there exists a desire to have that pain acknowledged (Ahmed 29). Scarry, in The Body in Pain: The Making and Unmaking of the World, maintains that understanding the pain of another, or sharing the experience of your own pain is not possible as pain destroys language and no words exist to adequately describe it (4). Though residing in another's body to know their pain is impossible, I question if pain might be understood through recognizing the experience of one's own pain in that of another. The damaged bodies in Marks of Obsession question if the pain felt by a socially damaged body were worn on the body and expressed through the body, through a painful desire to transform, could it be understood and acknowledged by others? 


\section{CONCLUSION}

This research creatively explores appearance, transformation, and pain in relation to the abject female body. The material experimentation inspired an exploration of my body in relation to social ideals. The transformed images that form the body of creative work consider how the self is embodied through various experiences of transformation and visualized through selfobjectifi ation and pain.

\section{The research and the} creative work are both very personal and maintain a deep reservoir of knowledge that manifested only through the experience of making. Using an autoethnographic methodology, this work captures my lived experiences and my reflections on those experiences.

It contributes to the field of practice-led research and feminist body theory, engages with existing discourse on body image and responds to ideal images of bodies disseminated by the fashion industry. 
Ahmed, Sara. The Cultural Politics of Emotion Second Edition. Routledge, 2015.

Barrett, Estelle. "Experiential Learning in Practice as Research: Context, Method, Knowledge." Journal of Visual Art Practice, vol.6, no. 2, 2007, pp. 115-124.

Blackman, Lisa. The Body: The Key Concepts. Berg, 2008.

Bordo, Susan. Unbearable Weight: Feminism, Western Culture, and the Body. University of California Press, 1993, 2003.

Butler, Judith. Gender Trouble: Feminism and the Subversion of Identity. Routledge, 1990.

Calogero, Rachel M., Stacey Tantleff-Dunn \& J. Kevin Thompson. Self-

Objectification in Women: Causes, Consequences and Counteractions. American Psychological Association, 2011.

Chaplin, Elizabeth. "The Photodiary as an Autoethnographic Method." The SAGE Handbook of Visual Research Methods, edited by Margolis, Eric and Luc Pauwels. SAGE Publications, 2011.

Chrisler, Joan C. \& Ingrid Johnston-Robledo. Woman's Embodied Self: Feminist Perspectives on Identity and Image. American Psychological Association, 2018.

Coleman, Rebecca. Transforming Images - Screens, Affect, Futures. Routledge, 2013.

Fahs, Breanne. "Mapping 'Gross' Bodies: The Regulatory Politics of Disgust” Aesthetic Labour: Rethinking Beauty Politics in Neoliberalism, edited by Elias, Ana Sofia, Rosiland Gill \& Christina Scharff. Palgrave, 2017, pp 83-100.

Featherstone, Mike. “The Body in Consumer Culture.”The Body: Social Process and Cultural Theory, edited by Featherstone, Mike, Mike Hepworth, and Brian S. Turner. London Sage, 1991, pp. 170-196.

Featherstone, Mike. "Body, Image and Affect in Consumer Culture", Body and Society, Vol 16 No. 1, 2010, pp. 193-221.

Firth, Hannah, \& Kate Gleeson. "Dressing the Body: The Role of Clothing in Sustaining Body Pride and Maintaining Body Distress." Qualitative Research in Psychology, Vol. 5, 2008, pp. 249-264.

Fine, G.A. and Deegan, J.G. "Three Principles of Serendipity: Insight, Chance, and Discovery in Qualitative Research", Qualitative Studies in Education, Vol. 9 No. 4, 1996, pp. 434-47.

Fraser, Mariam, and Monica Greco. The Body: A Reader. Routledge, 2005.

Fredrickson, B. L., and Roberts, T.-A. (1997). "Objectification Theory: Toward Understanding Women's Lived Experiences and Mental Health Risks”. Psychology of Women Quarterly, 21(2), 173-206. 
Grosz, Elizabeth. Volatile Bodies - Toward a Corporeal Feminism. Indiana University Press, 1994.

Kristeva, Julia. Powers of Horror: An Essay on Abjection. Translated by Leon S. Roudiez, New York: Columbia University Press, 1982.

Makela, Maarit. "Knowing Through Making: The Role of the Artefact in Practice-led Research.” Know Techn Pol, vol. 20, 2007, pp. 157-163.

Makri, Stephann, and Ann Blandford. "Coming Across Information Serendipitously: Part 1 - A Process Model [Open Access Version].” Journal of Documentation vol. 68, no. 5, 2012a., 684-705. doi:10.1108/00220411211256030.

Ringrose, Jessica and Valerie Walkerdine. "Regulating the Abject: The TV Make-Over as a Site of Neo-Liberal Reinvention Towards Bourgeois Femininity." Feminist Media Studies, vol. 8, no. 3, 2008, pp. 227-246.

Scarry, Elaine. The Body in Pain - The Making and Unmaking of the World, Oxford University Press, 1985.

Skains, R. Lyle. “Creative Practice as Research: Discourse on Methodology”, Media Practice and Education, 2018, vol. 19, no. 1, pp 82-97

DOI: $10.1080 / 14682753.2017 .1362175$

Wissinger, Elizabeth, A. This Year's Model: Fashion, Media and the Making of Glamour. New York University Press, 2015. 


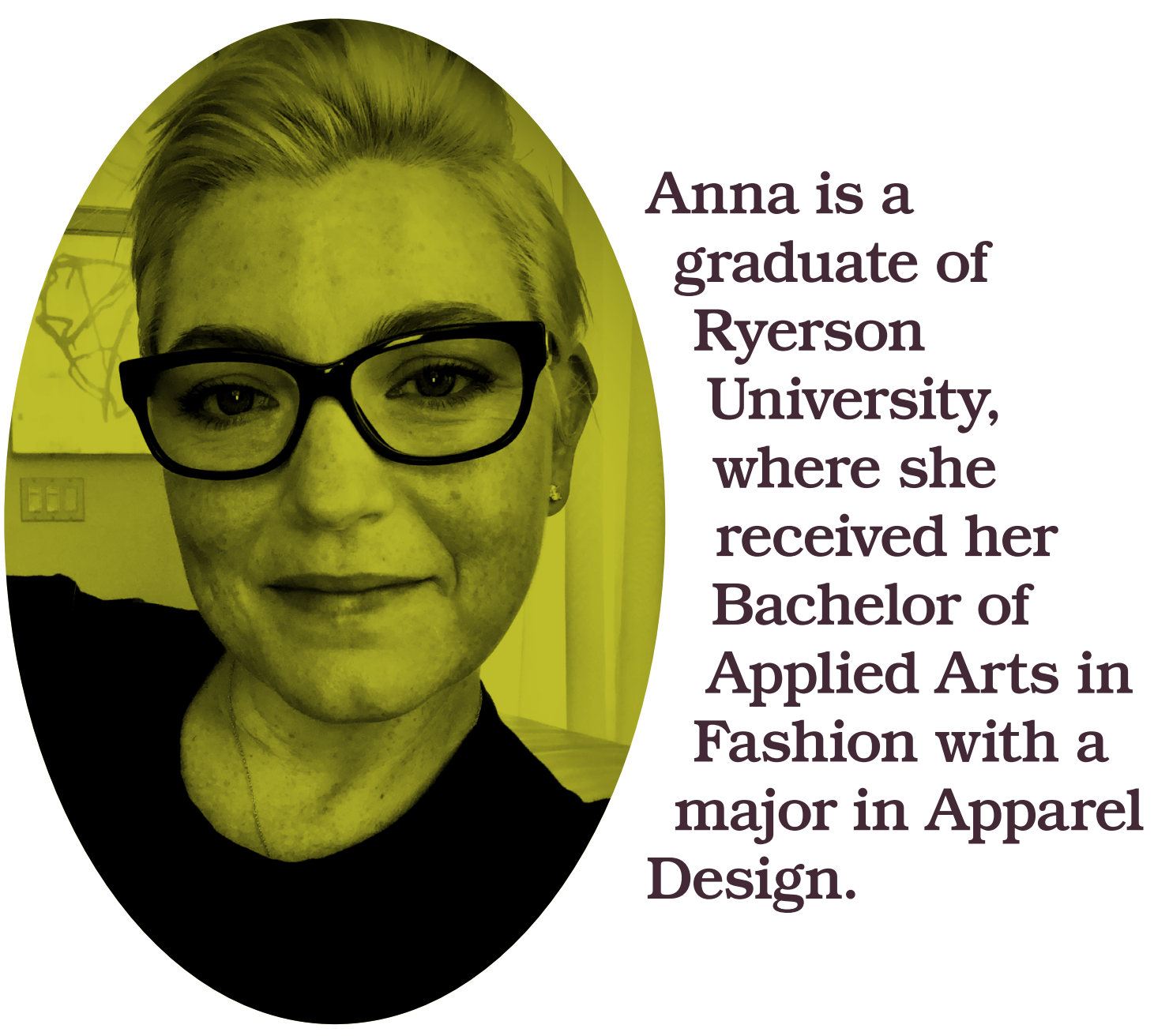

After two decades of fashion industry experience, with lead roles in design and product development working with Canadian industry leaders, Anna returned to Ryerson and received a Masters of Art in Fashion Studies. Anna is currently completing a Masters of Fine Art at OCAD University. Her creative explorations engage with transformation of the female body in relation to beauty ideals, identity creation, and obsession. She brings her unique perspective through various mediums.

\section{ARTICLE CITATION}

Marks of Obsession: Appearance, Transformation, Pain, and the Abject Female Body." Fashion Studies, vol. 3, no. 2, 2021, pp. 1-23, https://www.fashionstudies.ca/marks-of-obsession, https://doi.org/10.38055/FS030203 


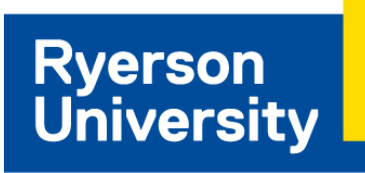

Fashion

Faculty of Communication

\& Design

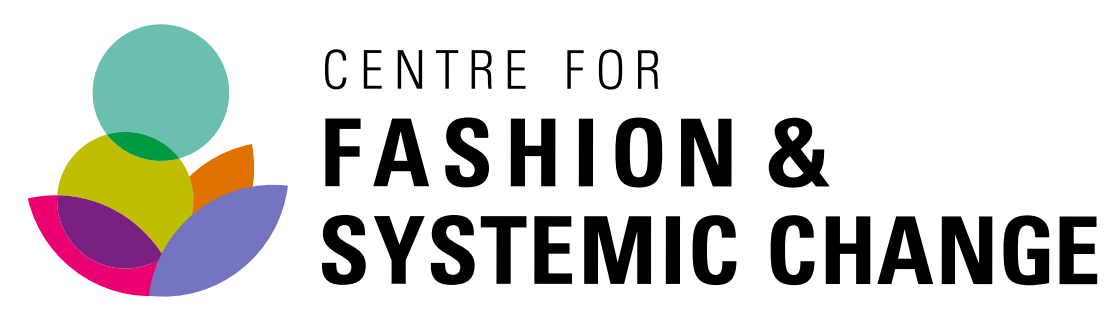

Frows $\mathrm{SH} / \mathrm{ON}$

ISSN 2371-3453

Copyright (C) 2021 Fashion Studies - All Rights Reserved

Creative Commons Attribution-NonCommercial-NoDerivatives 4.0 International (CC BYNC-ND 4.0) license (see: https://creativecommons.org/licenses/by-nc-nd/4.0/) 